\title{
Drug Targeting to Macrophages With Solid Lipid Nanoparticles Harboring Paromomycin: an In Vitro Evaluation Against L. major and L. tropica
}

\author{
Maryam Heidari Kharaji, ${ }^{1}$ Delaram Doroud, ${ }^{2}$ Tahereh Taheri, ${ }^{1}$ and Sima Rafati ${ }^{1,3}$
}

Received 2 August 2015; accepted 19 October 2015; published online 9 November 2015

\begin{abstract}
Leishmaniasis is a worldwide disease that leads to high mortality and morbidity in human populations. Today, leishmaniasis is managed via drug therapy. The drugs that are already in clinical use are limited to a number of toxic chemical compounds and their parasite drug resistance is increasing. It is therefore essential, in order to circumvent the current difficulties, to design a new anti-leishmanial drug treatment strategy. Besides producing new, active anti-leishmanial entities, another promising strategy could be developing novel delivery systems and formulations of the existing pharmaceutical ingredients to improve drug efficacy. In the present study, paromomycin sulfate (PM), as one of the promising antileishmanial drugs, was formulated in solid lipid nanoparticles (SLN), and its in vitro efficacy was investigated against different strains of Leishmania using a MTT test, Parasite-Rescue-Transformation-Assay, SYTO Green staining, and fluorescent microscope imaging. The results show that PM-loaded SLN is significantly more effective than PM in inhibiting parasite propagation $(P<0.05)$ and that cytotoxicity of PM-SLN formulations is size dependent. According to our results, delivery of the drugs to the macrophages via nanoparticle utilization seems to be an accessible and practical approach.
\end{abstract}

KEY WORDS: cutaneous leishmaniasis; drug delivery system; paromomycin sulfate; solid lipid nanoparticle.

\section{INTRODUCTION}

Leishmaniasis is one of the parasitic diseases caused by genus Leishmania (1). Leishmania parasites are dimorphic and change during their life cycle between two forms of promastigotes and amastigotes. Clinically, Leishmania parasites cause several forms of diseases in humans, including cutaneous leishmaniasis (CL), visceral leishmaniasis (VL), and mucocutaneous leishmaniasis (MCL) (1). As a neglected disease, the resources invested in the detection, treatment, and monitoring of leishmaniasis are extremely limited. Unlike VL, CL mortality is rare and is usually reported as being related to the co-infections with other diseases including malaria, or more recently, HIV, or the side effects of treatment (2). Cutaneous leishmaniasis is the most frequent form of leishmaniasis caused by species such as Leishmania major, Leishmania tropica, and Leishmania aethiopica in the old world and Leishmania mexicana, Leishmania amazonensis, and Leishmania guyanensis in the new world (3). CL is confined to the skin and is a self-healing disease with treatment duration depending on the infecting species. CL can, however, evolve into a more severe disease, such as MCL (2). Each

\footnotetext{
${ }^{1}$ Department of Immunotherapy and Leishmania Vaccine Research, Pasteur Institute of Iran, Tehran, Iran.

${ }^{2}$ Regulatory Department, Production and Research Complex, Pasteur Institute of Iran, Tehran, Iran.

${ }^{3}$ To whom correspondence should be addressed. (e-mail: s_rafati@yahoo.com)
}

year, 1.5 million new cases of CL are reported (4). To date, there is no effective treatment against CL and current therapies often fail and have many restrictions. Currently, pentavalent antimonials are the first-line treatment for CL. Antimonials are contraindicated in older individuals, during pregnancy, and in the patients suffering from renal and cardiac diseases. Pentavalent antimonials require daily injections and treatment duration is rather long. Resistance to pentavalent antimonials is increasing $(5,6)$. Due to the antimonial resistance issue, amphotericin B (AMB) has been introduced as a first-line treatment. Its toxicity along with its cost are the most highlighted limitations of its utilization $(7,8)$. One of the most promising drugs for anti-leishmanial chemotherapy is paromomycin sulfate (PM). Considering toxicity and cost, PM could be a good choice for treatment. In 1960, the antiLeishmania activity of PM was first reported (9). PM is an aminoglycoside antibiotic, effective against CL and VL. PM disrupts the mitochondrial membrane potential, inhibits protein synthesis, and its site of action is $16 \mathrm{~S}$ ribosomal subunit (10). In addition, PM changes the lipid metabolism, the fluidity of the membrane, and the mitochondrial operation (11). Due to its chemical structure, PM is a hydrophilic compound with a high molecular weight. Its physicochemical properties contribute to insufficient concentration of PM at the sites of infection after topical administration (12). The lack of an effective drug against CL has recently prioritized the creation of new, alternative therapeutic drugs. To this end, various pharmaceutical formulations have been assessed for the treatment of CL $(9,13-15)$. The effects of the topical form of PM in 
clinical trials for the treatment of CL have been promising, but due to the powerful barrier nature of the skin, this form of PM is not always effective (16-18). Lipid-based formulation of PM, i.e., liposomal PM, was prepared and its topical effects on the treatment of leishmaniasis evaluated $(9,14)$. Recently, solid lipid nanoparticles (SLN) have received much attention due to advantages, such as low cost and safety, compared to other colloidal nanoparticles (19). Solid lipid nanoparticles were introduced in 1990 (20). SLN is composed of a solid lipid core and emulsifiers with a size less than $1000 \mathrm{~nm}$. The lipid core matrix has an important role in controlling drug release $(21,22)$. The use of physiological lipids enhances biocompatibility and safety of the formulations based on SLN (23). Both hydrophilic and lipophilic pharmaceutical ingredients can be formulated into SLN (24). The pharmaceutical applications of SLN have been evaluated in different studies (25-29). The preparation of PM-loaded SLNs (PM-SLN) has been described previously (30). In the present study, SLN is used as a PM delivery system (Fig. 1), and the in vitro efficacy of the resulting formulation was evaluated against $L$. major and L. tropica. It is worth mentioning that both L. major and L. tropica are the most common strains in specific countries such as Iran, Iraq, and Afghanistan (31).

\section{MATERIAL AND METHODS}

\section{Reagents}

PM sulfate (P5057) was purchased from Sigma-Aldrich (USA). SYTO Green, sodium dodecyl sulfate (SDS), M199, RPMI-1640, dimethyl sulfoxide (DMSO), phorbol 12myristate 13-acetate (PMA), and 3-(4,5 dimethylthiazol-2yl)-2,5-diphenyl tetrazolium bromide (MTT) were obtained from Sigma-Aldrich (USA). RPMI-1640 and fetal calf serum (FCS) were obtained from Gibco (Germany).

\section{Preparation of PM-SLN}

A modified high shear homogenization (HSH) microemulsion technique was used to prepare PM-SLN as previously described $(30,32)$. Briefly, lipid (stearic acid) was heated to $85^{\circ} \mathrm{C}$. Tween $80(0.75 \%)$ was dispersed in the melted

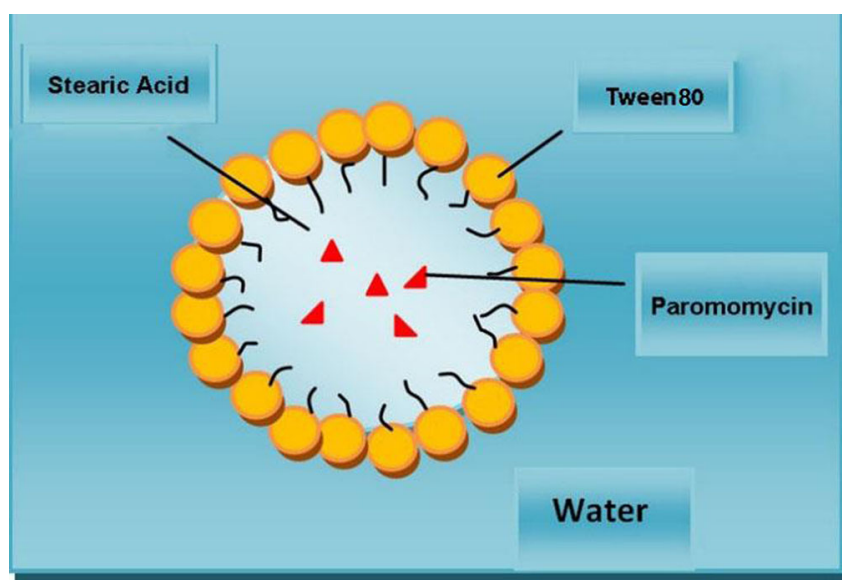

Fig. 1. Schematic diagram of solid lipid nanoparticles (SLN) lipid until the dispersion appeared clear. The aqueous phase containing paromomycin $\left(90 \mathrm{mg}\right.$ ) was heated to $85^{\circ} \mathrm{C}$ and added to the melted lipid under stirring. The lipid/drug ratio was adjusted to 4. Afterwards, the resulted emulsion was subjected to high shear homogenizer (IKAUltra-Turrax, T25, Germany) at 18,000 rpm for $20 \mathrm{~min}$. The resulted nanoemulsion was immediately dispersed in cold double distilled water $\left(2-5^{\circ} \mathrm{C}\right)$ followed by stirring to solidify the nanoparticles. The properties of each PM-SLN formulation such as size, polydispersity index, \% paromomycin loading, zeta potential, and entrapment efficiency were determined. The particle diameter of each sample was measured in triplicate by dynamic light scattering (Malvern, Nano-ZS, UK) as previously described $(30,32)$.

\section{Parasite}

The L. major strain (MRHO/IR/75/ER) and L. tropica strain (MOHM/IR/09/Khamesipour-Mashhad) were used in this experiment. Promastigotes were grown at $26^{\circ} \mathrm{C}$ in $\mathrm{M} 199$, $\mathrm{pH} 7.4$, supplemented with $5 \%$ FCS for L. major and $10 \%$ FCS for L. tropica.

\section{Cell Culture}

Human monocyte cell line THP1 (ATCC® TIB-202 ${ }^{\mathrm{TM}}$ ) were grown at $37^{\circ} \mathrm{C}$ in the presence of $5 \% \mathrm{CO}_{2}$ in RPMI-1640 supplemented with $10 \%$ fetal calf serum. Cells were counted and then treated with $5 \mu \mathrm{g} / \mathrm{ml}$ phorbol 12 -myristate 13-acetate (PMA) to form adherent cells. PMA-treated THP1 was used for further experiments.

\section{Cytotoxicity Evaluations}

The cytotoxicity was investigated by cultivating PMAtreated THP1 $\left(5 \times 10^{6}\right.$ cells $)$ in the presence of different concentrations (25-50-100-200-400-800-1600-3200-6400 $\mu \mathrm{g} / \mathrm{mL})$ of PM-SLN formulation (PM-SLN 15\% (120, 980, $1500 \mathrm{~nm})$, PM-SLN 12.5\% (240 nm)), PM, and blank SLN (as controls) in 96-well culture plates (Orange Scientific, E.U.) for $48 \mathrm{~h}$ at $37^{\circ} \mathrm{C}$. Cell viability was assessed by colorimetric assays using MTT reagent $(33,34)$. Absorbance rates were measured at optical density (OD) of $570 \mathrm{~nm}$. Results were expressed as the mean percentage reduction of THP1 cells compared with non-treated control samples and shown by $50 \%$ inhibitory concentration THP-1 cells $\left(\mathrm{CC}_{50}\right)$.

\section{Promastigote Drug Susceptibility Assay}

The efficacy of the different PM-SLN formulation (PM-SLN 15\% (120 nm), PM-SLN 12.5\% (240 nm)) concentrations $(25-50-100-200-400-800-1600-3200 \mu \mathrm{g} / \mathrm{mL})$ on the stationary phase of L. major and L. tropica promastigote form $\left(2 \times 10^{7}\right.$ parasites $)$ was assessed in a 48 - $\mathrm{h}$ time period, at $26^{\circ} \mathrm{C}$. Drug susceptibility was examined by MTT assay $(35,36)$ and $50 \%$ concentration of the drug causing $50 \%$ inhibition in promastigotes growth $(\mu \mathrm{g} / \mathrm{ml})$ was calculated $\left(\mathrm{IC}_{50}\right)$. 
Infection of the THP-1 With $L$. major and $L$. tropica Promastigotes and $\mathbf{E C}_{50}$ Determination

PMA-treated THP1 $\left(5 \times 10^{5}\right.$ cells $)$ were plated in 96-well culture plate and chamber slide (Thermo Scientific, USA) in RPMI-1640 medium supplemented with 10\% FCS. After $24 \mathrm{~h}$ of incubation at $37^{\circ} \mathrm{C}$ in $5 \% \mathrm{CO}_{2}$, stationary phase promastigotes of $L$. major and L. tropica were added to the wells (1:20 THP1 cell to parasite) and the cultures were incubated at $37^{\circ} \mathrm{C}$ in $5 \% \mathrm{CO}_{2}$ for $24 \mathrm{~h}$ allowing the parasites to infect the cells. Afterwards, free parasites were removed by washing with serum-free RPMI-1640 medium and the infected THP-1 were treated with different concentrations of drugs as mentioned previously for $48 \mathrm{~h}$ at $37^{\circ} \mathrm{C}$ in $5 \% \mathrm{CO}_{2}$.

\section{Parasite-Rescue-Transformation-Assay}

The infected PMA-treated THP1 in 96-well culture plate from the previous step was washed with serum-free RPMI1640 medium. Then, RPMI-1640 with $0.05 \%$ SDS was added to each well for cell lysis. The plate was shaken for $30 \mathrm{~s}$ and complete Schneider culture medium (supplemented with $10 \%$ FBS) was added to each well. The plates were incubated at $26^{\circ} \mathrm{C}$ for $72 \mathrm{~h}$ in order to transform the rescued amastigotes to promastigote form. After $72 \mathrm{~h}$ incubation at $26^{\circ} \mathrm{C}$, all the rescued live amastigotes were transformed into promastigote forms. The effect of the formulations was evaluated by MTT and $\mathrm{EC}_{50}(\mu \mathrm{g} / \mathrm{ml})(50 \%$ effective concentration) was determined (37).

\section{SYTO Green Staining and Fluorescent Microscope Imaging}

After $48 \mathrm{~h}$, each well of chamber slide containing the infected PMA-treated THP1 with prepared formulations was washed with serum-free RPMI-1640 medium. Afterwards, methanol was used to fix the cells. After drying, the slide was stained with SYTO Green staining solution (100 nM) in dark conditions at room temperature. After $15 \mathrm{~min}$, the slide was washed with water and allowed to dry. The digital images of THP1 were taken with an Epi-fluorescence microscope (Nikon, E200, Japan) (37). THP1 cells infection rate was calculated by the following equation (38):

$\%$ of cell infection $=\frac{\text { Number of infected cell }}{\text { Total of THP1 cell }} \times 100$

\section{Statistical Analysis}

Statistical analysis and $\mathrm{CC}_{50}, \mathrm{ED}_{50}$, and $\mathrm{IC}_{50}$ were calculated using GraphPad Prism (version 5.0; GraphPad Software, Inc 2007, San Diego, CA, USA). Student's $t$ test was used for the comparison between groups. The $P$ value $<0.05$ was considered significant.

\section{RESULTS}

\section{PM-SLN Formulation}

In our previous investigation, different criteria including the type of methods (microemulsion or solvent diffusion) and kind of lipid (cetyl palmitate or stearic acid) were comparatively studied. Their effects on average diameter, size distribution, and entrapment efficiency of the lipid nanoparticles for maximized entrapment efficiency, size particle reduction, and distribution were determined (32). Three quantitative factors-paromomycin content, weight fraction of Tween 80, and drug-to-lipid ratio-were also investigated at two levels for SLN formulation in a fractional factorial design (32). Briefly, the obtained results indicated that microemulsion was the most efficient method and stearic acid was the preferred lipid for SLN formulation (32). The size, polydispersity index, the percent of paromomycin loading, and the zeta potential of the particles are shown in Table I. The average size of the particle was reported to be $299.08 \mathrm{~nm}$. The drug released from the PM-SLN nanoparticulate formulation gradually and lasted $24 \mathrm{~h}$ in the aqueous media. The average entrapment efficiency of the prepared formulations was reported to be $42-46 \%(30,32)$.

\section{Cytotoxicity Evaluation}

The results of a MTT test indicated that blank SLN and $\mathrm{PM}$ are non-toxic for the cells, even at high concentrations (25-6400 $\mu \mathrm{g} / \mathrm{ml}$ ), as shown in Fig. 2a, b. The obtained $\mathrm{CC}_{50}$ for both PM and blank SLN was $6400 \mu \mathrm{g} / \mathrm{ml}$. The PM-SLN 15\% with the size of $980 \mathrm{~nm}$ and the PM-SLN $15 \%$ with the size of $1500 \mathrm{~nm}$ were cytotoxic and therefore were excluded from further efficacy evaluation (Fig. 2c, d). $\mathrm{CC}_{50}$ of the PM-SLN $15 \%$ with the size of 980 and $1500 \mathrm{~nm}$ was 80 and $70 \mu \mathrm{g} / \mathrm{ml}$, respectively. PM-SLN $12.5 \%(240 \mathrm{~nm})$ and PM-SLN $15 \%$ $(120 \mathrm{~nm})$ were only toxic for cells at higher concentrations $(6000 \mu \mathrm{g} / \mathrm{ml})$ as indicated in Fig. 2e, f. For PM-SLN 15\% $(120 \mathrm{~nm})$ and PM-SLN $12.5 \%(240 \mathrm{~nm})$, the $\mathrm{CC}_{50}$ was 4000 and $4500 \mu \mathrm{g} / \mathrm{ml}$, respectively.

\section{Effects of Formulation on Promastigotes and IC $_{50}$ Evaluation}

The $\mathrm{IC}_{50}(\mu \mathrm{g} / \mathrm{ml})$ of formulations for $L$. major and L. tropica are shown in Fig. 3, panels 1 and 2, respectively. Blank SLN has no effect on L. major and L. tropica promastigotes (Fig. 3, panels 1, 2: a and e). The results for L. major promastigote revealed that PM-SLN is more effective than PM $(P<0.05) . \mathrm{IC}_{50}$ of PM was $3100 \mu \mathrm{g} / \mathrm{ml}$ (Fig. 3, panel 1, b) and of both formulations of PM-SLN (15 and $12.5 \%$ ) was $1600 \mu \mathrm{g} / \mathrm{ml}$ (Fig. 3, panel 1, c and d). The results for L. tropica promastigote were almost identical to those of

Table I. Properties of Various PM-SLN Formulations Utilized in This Study. The Size, Polydispersity Index, \% Paromomycin Loading, and Zeta Potential Are Shown for Each Formulation

\begin{tabular}{llll}
\hline Formulations & Size $(\mathrm{nm})$ & Zeta potential & $\begin{array}{c}\text { Polydispersity } \\
\text { index }\end{array}$ \\
\hline PM-SLN 15\% & 120 & $532.43 \pm 164.40$ & $0.67 \pm 0.05$ \\
PM-SLN 15\% & 900 & $572.43 \pm 120.40$ & $0.57 \pm 0.05$ \\
PM-SLN 15\% & 1500 & $506.43 \pm 214.40$ & $0.25 \pm 0.05$ \\
PM-SLN 12.5\% & 240 & $507.97 \pm 250.47$ & $0.57 \pm 0.05$ \\
\hline
\end{tabular}

The values are means \pm standard deviations $(n=3)$. The mean entrapment efficiency was found to be (42-46\%) in all formulations 


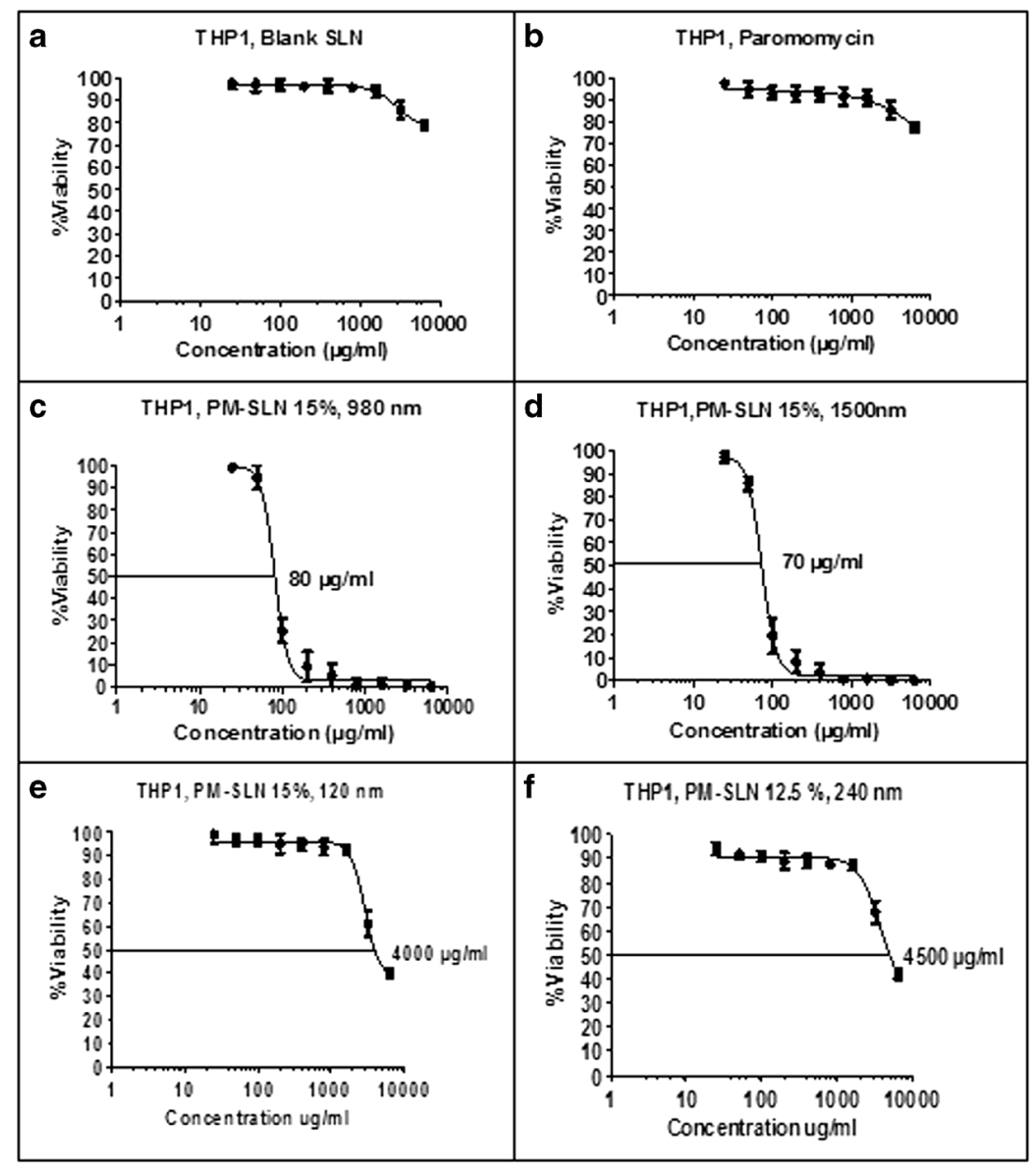

Fig. 2. Cytotoxicity evaluation using THP-1 cell line. Blank SLN and PM (a, b) are nontoxic for the cells (25-6400 $\mu \mathrm{g} / \mathrm{ml})$. PM-SLN 15\% (980 nm) and PM-SLN 15\% (1500 nm) (c, d) are cytotoxic. PM-SLN $15 \%(120 \mathrm{~nm})$ and PM-SLN $12.5 \%(240 \mathrm{~nm})(\mathbf{e}, \mathbf{f})$ are only toxic for cells at higher concentrations $(6400 \mu \mathrm{g} / \mathrm{ml})$

L. major promastigote (Fig. 3, panel 2). For L. tropica promastigote, $\mathrm{IC}_{50}$ of PM was $3200 \mu \mathrm{g} / \mathrm{ml}$ (Fig. 3, panel 2, f) and $\mathrm{IC}_{50}$ of PM-SLN 15 and $12.5 \%$ was 1600 and $1700 \mu \mathrm{g} / \mathrm{ml}$, respectively (Fig. 3, panel 2, g and h). By comparing the formulation $\mathrm{IC}_{50}$, the effectiveness of the PM-SLN formulations is evident $(P<0.05)$ (Fig. 3). The inhibitory effect of PM and PM-SLN formulations is significantly different $(P<0.05)$.

\section{Parasite-Rescue-Transformation-Assay and $\mathbf{E C}_{50}$ Determination}

The $\mathrm{EC}_{50}(\mu \mathrm{g} / \mathrm{ml})$ of formulation for $L$. major and L. tropica amastigote forms are shown in the Fig. 4, panels 1 and 2, respectively. It shows that for L. major amastigote, the $\mathrm{EC}_{50}$ of PM was $1600 \mu \mathrm{g} / \mathrm{ml}$ (Fig. 4, panel 1, b) and for PMSLN 15 and $12.5 \%$ was 390 and $800 \mu \mathrm{g} / \mathrm{ml}$, respectively (Fig. 4, panel 1, c and d). For L. tropica amastigote, the $\mathrm{EC}_{50}$ of PM was $1600 \mu \mathrm{g} / \mathrm{ml}$ (Fig. 4, panel 2, f), and for PM-SLN 15 and $12.5 \%$ was 400 and $750 \mu \mathrm{g} / \mathrm{ml}$, respectively (Fig. 4, panel 2, g and $\mathrm{h}$ ). There were significant differences in the inhibitory effect of the PM and PM-SLN formulations against L. major and $L$. tropica amastigotes $(P<0.05)$ (Fig. 4$)$. As the cytotoxicity results showed, the $\mathrm{CC}_{50}$ of PM-SLN $12.5 \%(240 \mathrm{~nm})$ and
PM-SLN 15\% (120 nm) was 4500 and $4000 \mu \mathrm{g} / \mathrm{ml}$ (Fig. 2e, f). Considering the $\mathrm{EC}_{50}$ of the formulations, this means $390 \mu \mathrm{g} / \mathrm{ml}$ of PM-SLN $15 \%(120 \mathrm{~nm})$ and $800 \mu \mathrm{g} / \mathrm{ml}$ of PMSLN $12.5 \%$ (Fig. 4, panel 1, c and d) are toxic to cells, but also inhibit the propagation of L. major amastigotes. Correspondingly, the results for L. tropica showed 400 and $750 \mu \mathrm{g} / \mathrm{ml}$ of PM loaded in SLN (15 and 12.5\%) (Fig. 4, panel 2 , $g$ and $\mathrm{h}$ ) can also inhibit L. tropica amastigotes while being non-toxic to the cells.

\section{SYTO Green Staining and Fluorescent Microscope Imaging}

The digital images of infected THP1 cells with L. major and L. tropica were taken with a fluorescent microscope (Fig. 5a, b). As mentioned previously, the infection percent of the THP1 cells with parasite (L. major and L. tropica) after treatment with PM-SLN (15\%), PM-SLN (12.5\%), and PM were determined with the equation that was previously mentioned and the results are summarized in the Table II. The percentage of infections for the $L$. major-infected THP1 cells after treatment with $400 \mu \mathrm{g} / \mathrm{ml}$ PM-SLN (15\%), PM-SLN (12.5\%), and PM was 48.5, 62.5, and 68.0 , respectively. With $800 \mu \mathrm{g} / \mathrm{ml}$ of each drug, the percentage was 37.0, 53.0, and 61.5, and after treatment with $1600 \mu \mathrm{g} / \mathrm{ml}$, it 


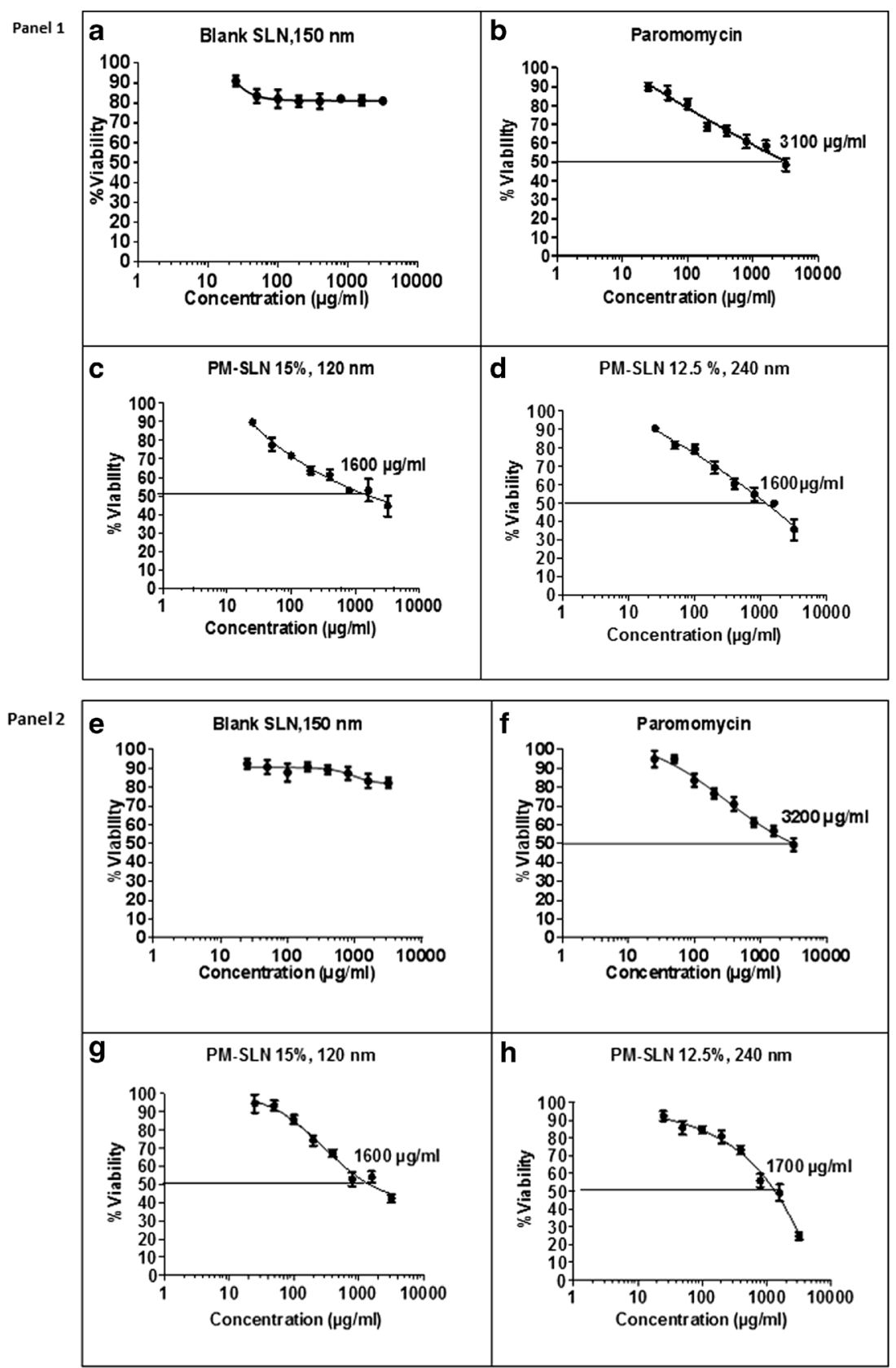

Fig. 3. The inhibitory effect of drugs on L. major (panel 1) and L. tropica (panel 2) promastigotes. The effect of drugs on $L$. tropica and $L$. major promastigotes is the same. Blank SLN has no effect on the L. major and L. tropica promastigotes (panel 1 (a), panel 2 (e)). For L.major promastigotes, the $\mathrm{IC}_{50}$ of PM-SLN formulations (panel $1(c$ and $d)$ ) are lower than that of PM (panel $1(b)$ ) and this means the PM-SLN formulations are more effective. Similarly, for L. tropica promastigotes, the evaluation of $\mathrm{IC}_{50}$ shows that the PMSLN formulations (panel $2(g$ and $h)$ ) are more effective than PM (panel $2(f)$ ) for the inhibition of the parasite

was $23.5,33.0$, and 48.5 , respectively (Table II). The infection percentage for the L. tropica-infected THP1 cells after treatment with $400 \mu \mathrm{g} / \mathrm{ml}$ PM-SLN (15\%) was 48.0, with PM-SLN $(12.5 \%$ ) was 67.0 , and with PM was 69.0. Using $800 \mu \mathrm{g} / \mathrm{ml}$, it was $29.5,47.0$, and 61.5 , respectively. The percentage of infections after treatment with $1600 \mu \mathrm{g} / \mathrm{ml}$ PM-SLN (15\%) was 13.0, with PM-SLN (12.5\%) was 22.5, and with PM was 48.5 (Table II). The percentage of infections in infected cells treated with the
PM-SLN formulation is significantly lower than infected cells treated with PM $(P<0.05)$. As shown in Table III, $\mathrm{EC}_{50} / \mathrm{CC}_{50}$ of PM-SLN 15\% (120 nm) is lower than PM-SLN 12.5\% (240 nm), which indicates that the efficacy of PM-SLN $15 \%(120 \mathrm{~nm})$ is more than PM-SLN $12.5 \%$ (240 nm). As shown in Table IV, considering the size of the nanoparticle, the PM-SLN $15 \%$ $(120 \mathrm{~nm})$ is more effective and less toxic compared to PM-SLN $12.5 \%(240 \mathrm{~nm})$. 


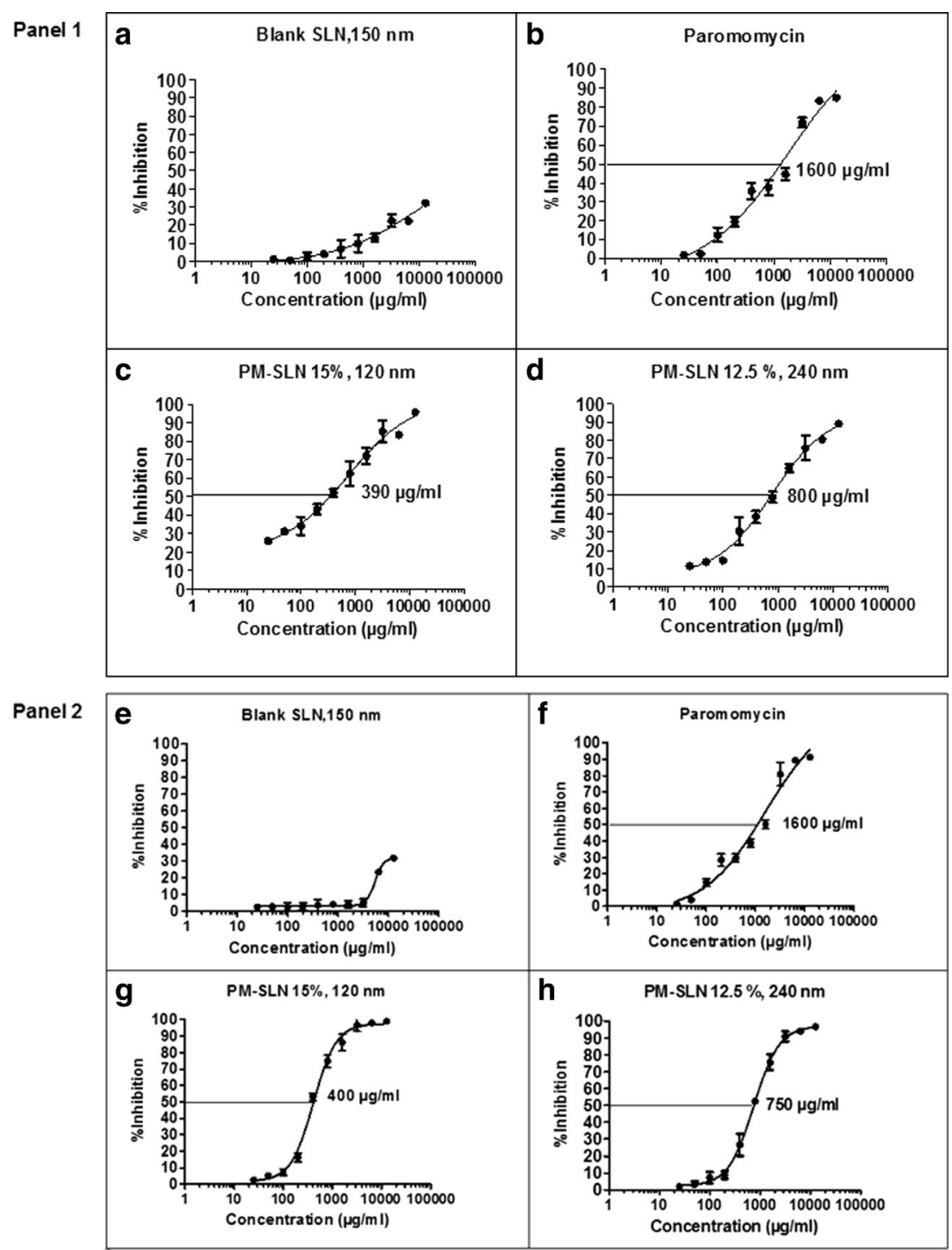

Fig. 4. Parasite-Rescue-Transformation-Assay for the amastigote form of L. major and L. tropica. The $\mathrm{EC}_{50}(\mu \mathrm{g} / \mathrm{ml})$ of the drug was computed and shown in the figure. $\mathrm{EC}_{50}$ of the PM and PM loaded in SLN (15, 12.5\%) for the L. major amastigote were 1600, 390, and $800 \mu \mathrm{g} / \mathrm{ml}$ (panel $1(c$ and $d)$ ), respectively, and for the $L$. tropica amastigote were $1600 \mu \mathrm{g} / \mathrm{ml}$ (panel $2(f)$ ), $750 \mu \mathrm{g} / \mathrm{ml}$, and $400 \mu \mathrm{g} / \mathrm{ml}$ (panel 2 ( $g$ and $h$ )). Considering the drug's $\mathrm{EC}_{50}$, PM-SLN formulations, as in the previous tests, were determined to have a greater inhibitory effect and a significant inhibition of amastigote propagation was observed when the SLN-PM formulation was used compared to PM

\section{DISCUSSION}

One of the most commonly used drugs for the treatment of cutaneous leishmaniasis is PM (39). Commercially available forms of PM are PM capsules (oral form), PM cream (topical form), and PM for injection (intramuscularly for VL) (39-41). PM formulations have some disadvantages, including a short half-life in plasma and rapid renal excretion (being a hydrophilic molecule with high molecular weight). All these factors decrease the concentration of PM at the sites of action, e.g., the reduction of PM oral absorption, thus making the oral administration of PM inefficient $(8,9,12,14)$. According to the data obtained from clinical trials, the effect of the topical form of PM for the treatment of cutaneous leishmaniasis has been promising, but due to the powerful barrier nature of the skin, it is not effective (16-18). One way to increase PM efficacy is to utilize a delivery system. In recent years, colloidal carriers, such as liposomes, emulsions, and polymeric nanoparticles, have been very promising in improving the bioavailability of the active pharmaceutical ingredients $(9,42,43)$. In one recent study, PM-loaded liposomes were developed and investigated as a drug delivery system $(8,9,12,14)$. The effect of PM formulated with stearylamine-bearing liposome on visceral leishmaniasis was investigated by Banerjee et al. (8). Jaafari et al. (2009) evaluated the effect of PM sulfate formulated with liposomes in the treatment of L. major-infected mice (9). It was reported that PM formulated with liposomes can help in controlling topical drug delivery (14). For the past decade, the use of SLN as an alternative carrier for colloidal drug delivery 


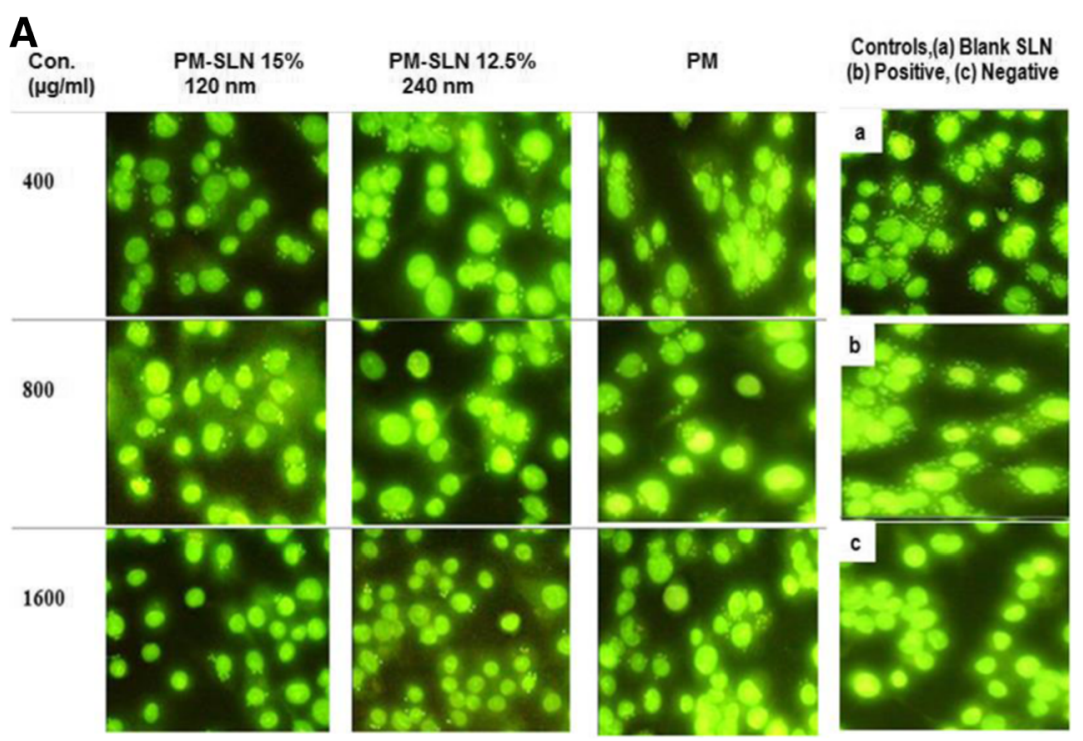

\section{B}

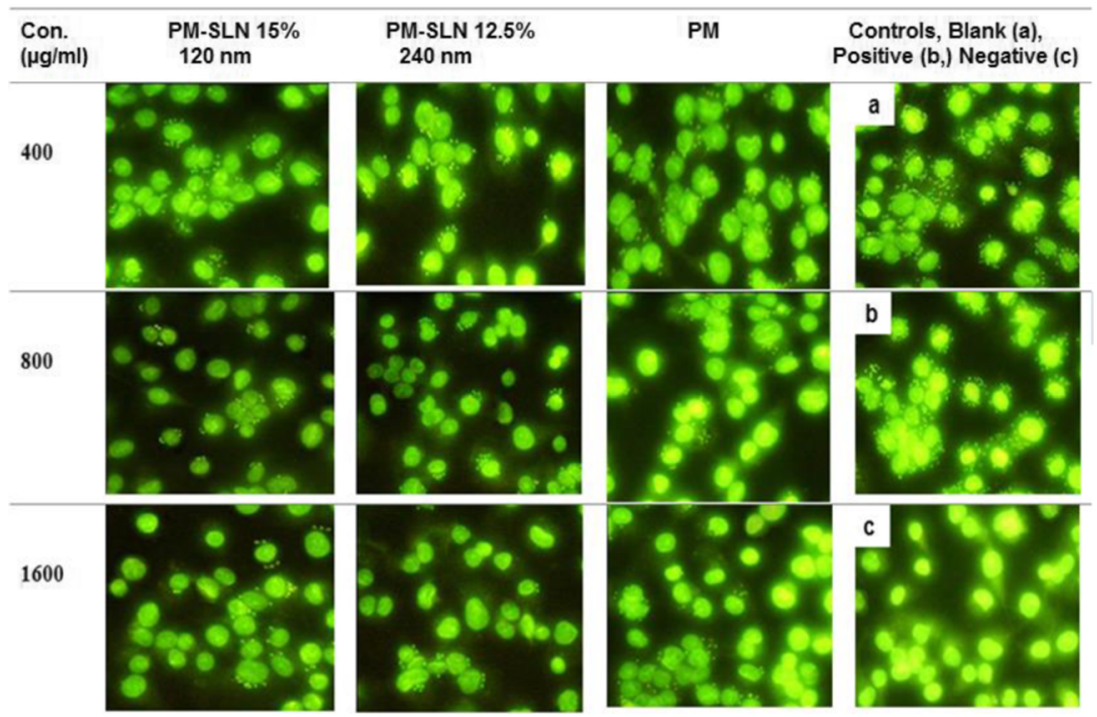

Fig. 5. SYTO Green staining and fluorescent microscope imaging of L. major (A) and L. tropica (B) infected cells after treatment with different concentrations of the drugs

Table II. \%Infection of L. major-Infected THP1 Cells in Panel a and L. tropica-Infected THP1 Cells in Panel b of Fig. 5 After Drug Treatment. For Both Parasites, the Percentage of Infection in Infected Cells Treated With the PM-SLN Formulation Is Significantly Lower Than Infected Cells Treated With PM (for L. major: a(1), b(1) $=* P<0.04 ; \mathrm{a}(1), \mathrm{c}(1)=* P<0.02 ; \mathrm{a}(2), \mathrm{b}(2)=* P<0.02 ; \mathrm{a}(2), \mathrm{c}(2)=* * P<0.001 ; \mathrm{a}(3)$, $\mathrm{b}(3)=* * P<0.002 ; \mathrm{a}(3), \mathrm{c}(3)=* * P<0.002 ; \mathrm{b}(3), \mathrm{c}(3)=* P<0.05)$. (For L. tropica: $\mathrm{a}(1), \mathrm{b}(1)=* P<0.01 ; \mathrm{a}(1), \mathrm{c}(1)=* P<0.02 ; \mathrm{a}(2), \mathrm{b}(2)=* P<0.01$; $\mathrm{a}(2), \mathrm{c}(2)=* * P<0.002 ; \mathrm{a}(3), \mathrm{b}(3)=* * P<0.005 ; \mathrm{a}(3), \mathrm{c}(3)=* * P<0.001 ; \mathrm{b}(3), \mathrm{c}(3)=* P<0.03)$

\begin{tabular}{|c|c|c|c|c|c|c|c|c|c|c|c|}
\hline \multirow{2}{*}{$\begin{array}{l}\text { Drugs } \\
\begin{array}{c}\text { Concentration } \\
(\mu \mathrm{g} / \mathrm{ml})\end{array}\end{array}$} & \multicolumn{3}{|c|}{ PM-SLN $15 \%^{a}$} & \multicolumn{3}{|c|}{ PM-SLN $12.5 \%{ }^{\mathrm{b}}$} & \multicolumn{3}{|l|}{$\mathrm{PM}^{\mathrm{c}}$} & \multirow{2}{*}{$\begin{array}{l}\text { Blank SLN } \\
400\end{array}$} & \multirow{2}{*}{$\frac{\text { No treatment }}{-}$} \\
\hline & $400(1)$ & $800(2)$ & $1600(3)$ & $400(1)$ & $800(2)$ & $1600(3)$ & $400(1)$ & $800(2)$ & $1600(3)$ & & \\
\hline $\begin{array}{l}\text { \% Infection } \\
\quad \text { for L. major }\end{array}$ & $48.5 \pm 1.5$ & $37.0 \pm 2.0$ & $23.5 \pm 1.5$ & $62.5 \pm 3.5$ & $53.0 \pm 2.8$ & $33.0 \pm 4.2$ & $68.0 \pm 4.2$ & $61.5 \pm 2.1$ & $48.5 \pm 4.9$ & $90.5 \pm 1.0$ & $98.5 \pm 1.5$ \\
\hline $\begin{array}{l}\% \text { Infection } \\
\quad \text { for L. tropica }\end{array}$ & $48.0 \pm 1.0$ & $29.5 \pm 0.5$ & $13.0 \pm 1.0$ & $67.0 \pm 3.5$ & $47.0 \pm 2.8$ & $22.5 \pm 3.5$ & $69.0 \pm 4.2$ & $61.5 \pm 2.1$ & $48.5 \pm 4.9$ & $91.0 \pm 1.5$ & $98.0 \pm 1.5$ \\
\hline
\end{tabular}

Different numbers in parentheses [(1), (2), (3)] represent different concentration: (1) 400, (2) 800, (3) 1600

${ }^{a}$ PM-SLN $15 \%$

${ }^{b}$ PM-SLN $12.5 \%$

${ }^{c} \mathrm{PM}$ 
Table III. Ratio Comparison of $\mathrm{EC}_{50}$ to $\mathrm{CC}_{50}$ for PM-SLN $15 \%$ $(120 \mathrm{~nm})$ and PM-SLN $12.5 \%(240 \mathrm{~nm})$. The $\mathrm{EC}_{50} / \mathrm{CC}_{50}$ of PM-SLN $15 \%(120 \mathrm{~nm})$ Is Lower Than PM-SLN $12.5 \%$ (240 nm)

\begin{tabular}{|c|c|c|c|c|c|}
\hline \multirow[t]{2}{*}{ Formulations } & \multirow[t]{2}{*}{$\mathrm{CC}_{50}(\mu \mathrm{g} / \mathrm{ml})$} & \multicolumn{2}{|c|}{$\mathrm{EC}_{50}(\mu \mathrm{g} / \mathrm{ml})$} & \multicolumn{2}{|c|}{$\mathrm{EC}_{50} / \mathrm{CC}_{50}$} \\
\hline & & & \multicolumn{3}{|c|}{ L. major } \\
\hline L. tropica & L. major & & & & \\
\hline \multicolumn{6}{|l|}{ L. tropica } \\
\hline $\begin{array}{l}\text { PM-SLN 15\% } \\
\quad(120 \mathrm{~nm})\end{array}$ & 4000 & 390 & 400 & 0.097 & 0.100 \\
\hline $\begin{array}{l}\text { PM-SLN } 12.5 \% \\
\quad(240 \mathrm{~nm})\end{array}$ & 4500 & 800 & 750 & 0.177 & 0.166 \\
\hline
\end{tabular}

systems like liposomes, fat emulsions, and polymeric nanoparticles has been considered due to their advantages over other colloidal carriers $(21,23,44)$. Previously, Ghadiri et al. (2012) reported that loading PM into SLN formulation can control the release profile of the drug (30). In the present study, we assessed the efficacy and safety of the PM-SLN formulations in in vitro conditions for the first time. PM-SLN formulations with 15\% PM and $12.5 \%$ PM were prepared and evaluated against $L$. major and L. tropica. (30). Jaafari et al. (2009) used liposomes containing 10 or $15 \% \mathrm{PM}$ and evaluated the topical effect of the formulations on CL caused by L. major. El-On et al. (1984) revealed that $15 \%$ $\mathrm{PM}$ with $12 \%$ methyl benzethonium chloride $(\mathrm{MBCl})$ ointment is effective in the treatment of CL in BALB/c mice. Effectiveness of topical formulations of $15 \% \mathrm{PM}$ and $10 \%$ urea was reported $(9,45,46)$. Here, we evaluated the in vitro anti-leishmanial activity of PM-SLN formulation against two Leishmania species. The cytotoxicity results on the THP-1 cell line using the MTT test showed that PM alone and free solid lipid nanoparticles are not toxic for mammalian cells (20). It was reported that PM is not cytotoxic on HCT-8 cell (33). Schöler et al. (2002) investigated the cytotoxicity of SLN using the MTT test on murine peritoneal macrophages (34). Müller et al. (1997) found that SLN showed lower toxicity compared to polyalkylcyanoacrylate and PLA/GA (47). Another study evaluated the cytotoxicity of SLN using human granulocytes and reported that SLN was the least cytotoxic formulation (48). In the Weyenberg et al. (2007) study, they assessed the effect of SLN on mouse 3T3 fibroblasts, J774 macrophages, and $\mathrm{HaCaT}$ keratinocytes and evaluated cell viability utilizing the MTT test (49). Our results further suggest that the toxicity of PM-SLN formulations depends on the size and dose.
PM-SLN formulations with a smaller size and lower dose showed slight symptoms of toxicity, but PM-SLN formulations with a larger size and higher dose were toxic for the THP1 cell line. As indicated in our results (Table IV), the efficacy of the PM-SLN formulations is size dependent. PM-SLN formulations with a size of $120 \mathrm{~nm}$ showed better efficacy than PM-SLN formulations with a size of $240 \mathrm{~nm}$. PM-SLN formulations with a size of 980 and $1500 \mathrm{~nm}$ were toxic for the THP1 cell line in low concentrations $\left(\mathrm{CC}_{50}, 80\right.$ and $\left.70 \mu \mathrm{g} / \mathrm{ml}\right)$; therefore, their effect on the parasite was not pursued. Indeed, due to their large size, PM-SLN formulations $15 \%$ (980 and $1500 \mathrm{~nm}$ ) compared to PM-SLN formulations with $120 \mathrm{~nm}$, with the same percentage of PM (15\%), were more toxic. Also, toxicity of PM-SLN formulations 15\% (980 and $1500 \mathrm{~nm}$ ) is more than PM-SLN formulations with a lower percentage of PM (12.5\%) and a smaller size $(240 \mathrm{~nm})$. These results suggest that reducing the percentage of PM in the formulation has no effect on PM-SLN formulation toxicity. Efficacy of PM-SLN $15 \%(120 \mathrm{~nm})$ and PM-SLN 12.5\% (240 nm) for two types of parasite (L. major and L. tropica) were compared. In summary, efficacy of PM-SLN 15\% (120 nm) is higher than PM-SLN $12.5 \%$ $(240 \mathrm{~nm})$. Nanoparticle size effect on cytotoxicity and efficacy has already been evaluated (50-54). Lin et al. (2006) showed that larger $\mathrm{SiO}_{2}$ nanoparticles have a greater cytotoxicity than smaller Min-U-Sil quartz particles on human lung cancer cells (55). In another study by Carlson et al. (2008), it was reported that cytotoxicity of silver nanoparticles is size dependent (56). In the Lee et al. (2007) study, paclitaxel-loaded TM-SLNs showed dosedependent cytotoxicity against both OVCAR-3 and MCF-7 cells (57). It was reported that reaction of cells to nanoparticles depends on the size of the nanoparticles (58). The inhibitory effect of formulations on promastigotes was assessed using the MTT test and $\mathrm{IC}_{50}$ was analyzed. (35). According to our results, PM loaded in SLNs as delivery system can be more effective than PM for parasite inhibition. The results for L. major and L.tropica promastigote revealed that PM-SLN is more effective than PM $(P<0.05)$. For $L$. major promastigotes, the $\mathrm{IC}_{50}$ of $\mathrm{PM}$ was $3100 \mu \mathrm{g} / \mathrm{ml}$ and of both formulations of PM-SLN (15 and $12.5 \%$ ) was $1600 \mu \mathrm{g} / \mathrm{ml}$. The results for L. tropica promastigote were practically the same and $\mathrm{IC}_{50}$ of PM was $3200 \mu \mathrm{g} / \mathrm{ml}$ and $\mathrm{IC}_{50}$ of PM-SLN 15 and $12.5 \%$ was 1600 and $1700 \mu \mathrm{g} / \mathrm{ml}$, respectively. As the results show, $\mathrm{IC}_{50}$ of PM-SLN formulations is lower than $\mathrm{PM}$; this suggests that PM in formulation can inhibit the parasites propagation at lower concentrations. Khosravi et al. (2011) also used the MTT test for evaluation of the effect of various concentrations of nanosilver particle solutions on $L$. tropica promastigotes and determined a $50 \%$ inhibitory concentration (36). We used parasite rescue and transformation assay to evaluate the effect of PM-SLN formulations on the amastigote form of

Table IV. Effect of size on PM-SLN formulations efficacy. EC 50 of PM-SLN 15\% (120nm) for L. major and L. tropica is almost identical. Results of $\mathrm{EC}_{50}$ for PM-SLN $12.5 \%$ (240nm) are the same but the ratio of $\mathrm{EC}_{50}$ to $\mathrm{CC}_{50}$ for PM-SLN $15 \%$ (120nm) is lower than PM-SLN $12.5 \%$ $(240 \mathrm{~nm})$ and it means size of PM-SLN formulations could affect the drug efficacy

\begin{tabular}{|c|c|c|c|c|c|c|}
\hline \multicolumn{2}{|c|}{$\begin{array}{l}\text { Drugs: \% PM and } \\
\text { size of SLNs } \\
(\mathrm{nm})\end{array}$} & \multirow{2}{*}{$\begin{array}{l}\text { Toxicity on THP1 } \\
\text { cell line } \\
\left(\mathrm{CC}_{50}, \mu \mathrm{g} / \mathrm{ml}\right)\end{array}$} & \multirow{2}{*}{$\begin{array}{l}\text { Effect on L. major } \\
\quad \begin{array}{l}\text { amastigote } \\
\left(\mathrm{EC}_{50}, \mu \mathrm{g} / \mathrm{ml}\right)\end{array} \\
390\end{array}$} & \multirow{2}{*}{$\begin{array}{l}\text { Effect on } L . \text { tropica } \\
\text { amastigote } \\
\left(\mathrm{EC}_{50}, \mu \mathrm{g} / \mathrm{ml}\right)\end{array}$} & \multirow{2}{*}{$\begin{array}{l}\mathrm{EC}_{50} / \mathrm{CC}_{50} \text { for } \\
\quad \text { L. major } \\
0.097\end{array}$} & \multirow{2}{*}{$\begin{array}{l}\mathrm{EC}_{50} / \mathrm{CC}_{50} \text { for } \\
\text { L. tropica } \\
0.100\end{array}$} \\
\hline $15 \%$ & 120 & & & & & \\
\hline & 980 & 80 & - & - & - & - \\
\hline & 1500 & 70 & - & - & - & - \\
\hline $12.5 \%$ & 240 & 4500 & 800 & 750 & 0.177 & 0.166 \\
\hline
\end{tabular}


the L. major and L. tropica and the results showed that PMloaded SLN is more effective than PM. The results show that for $L$. major amastigote, the $\mathrm{EC}_{50}$ of $\mathrm{PM}$ was $1600 \mu \mathrm{g} / \mathrm{ml}$ and for PM-SLN 15 and 12.5\% was 390 and $800 \mu \mathrm{g} / \mathrm{ml}$, respectively. For L. tropica amastigote, the $\mathrm{EC}_{50}$ of $\mathrm{PM}$ was $1600 \mu \mathrm{g} / \mathrm{ml}$ and for PM-SLN 15 and $12.5 \%$ was 400 and $750 \mu \mathrm{g} / \mathrm{ml}$, respectively. According to the presented data, the $\mathrm{EC}_{50}$ of PM-SLN (for both parasites) is reduced to $1: 4$ for the $15 \%$ and $1: 2$ for the $12.5 \%$ formulations when compare to the non-formulated PM. According to the $\mathrm{EC}_{50}$ results, SLN can increase the effectiveness of the PM. Direct counting methods were applied for the assessment of drug efficacy against the intracellular amastigotes following the staining with Giemsa under microscopic investigation (5963 ). Counting cells takes a lot of time and counting the living parasites and defining the parasite viability through this assay is very difficult and, as a result, it may not be an accurate estimation of the $\mathrm{EC}_{50}$. Parasite rescue and transformation assay can be a good alternative assay to previous methods to evaluate the effect of drugs on the amastigote form of the parasite (37). In this study, SYTO Green staining and fluorescent microscope imaging were used for investigating the level of infection of treated cells. The SYTO Green staining technique stained the intracellular form of the parasite (37). It should be noted that there was a contrast between the color of the amastigote nucleus and the cytoplasm of the cell and the amastigote was easily diagnosed. SYTO Green staining and fluorescent microscope imaging results confirmed and indicated that infected cells treated with PM-SLN formulation had the lowest level of infection and this formulation had the better inhibitory effect. According to the biocompatibility of the SLN as a delivery system and the data from in vitro analysis of $\mathrm{IC}_{50}$ and $\mathrm{EC}_{50}$ PM-SLN formulation, it can be proposed that the presented formulation might be efficiently utilized in the treatment of the cutaneous leishmaniasis, if the in vivo and other ongoing clinical studies results satisfactory.

\section{CONCLUSION}

Leishmaniasis is a serious health problem in many countries. Despite of all efforts, there is no definite treatment against leishmaniasis. It seems necessary to develop new treatment strategies for leishmaniasis. The solid lipid nanoparticles utilized in the formulations of present study have effective roll as drug delivery systems for the treatment of leishmaniasis. SLN as delivery system can enhance the capability of PM to penetrate into the macrophage. Our results show that the PMSLN formulations were able to increase the efficacy of PM. Also, the efficacy of the PM-SLN formulations is size dependent. In addition, blank SLN is safe without any cytotoxicity. Therefore, PM-SLN formulation opens a new hope as antileishmanial compound against $L$. major and L. tropica infection. These promising findings could be completed by further in vivo investigation which is in progress. However, according to our results, delivery of the drugs to the macrophages via nanoparticle utilization seems to be accessible and practical, but requires further research in order to develop new costeffective strategies for the treatment of the leishmaniasis.

\section{ACKNOWLEDGMENTS}

We gratefully acknowledge S. Alizadeh (Department of Immunotherapy and Leishmania Vaccine Research, Pasteur
Institute of Iran) for his technical assistance. This work was financially supported by grants from the Pasteur Institute of Iran to M. Heidari Kharaji's PhD studentship.

\section{REFERENCES}

1. Dossin FM, Dufour A, Dusch E, Siqueira-Neto JL, Moraes CB, Yang GS, et al. Automated nuclear analysis of Leishmania major telomeric clusters reveals changes in their organization during the parasite's life cycle. PloS one. 2008;3(6):e2313.

2. Reithinger R. Leishmaniases' burden of disease: ways forward for getting from speculation to reality. PLoS Negl Trop Dis. 2008;2(10):e285.

3. Trufant JW, Lewin JM, Hale CS, Meehan SA, Pomeranz MK. New world cutaneous leishmaniasis. Dermatol Online J. 2015;20(12).

4. Momeni A, Rasoolian M, Momeni A, Navaei A, Emami S, Shaker Z, et al. Development of liposomes loaded with antileishmanial drugs for the treatment of cutaneous leishmaniasis. J Liposome Res. 2013;23(2):134-44.

5. Hadighi R, Boucher P, Khamesipour A, Meamar A, Roy G, Ouellette M, et al. Glucantime-resistant Leishmania tropica isolated from Iranian patients with cutaneous leishmaniasis are sensitive to alternative antileishmania drugs. Parasitol Res. 2007;101(5):1319-22.

6. Raju BS, Gurumurthy S, Kuhls K, Bhandari V, Schnonian G, Salotra P. Genetic typing reveals monomorphism between antimony sensitive and resistant Leishmania donovani isolates from visceral leishmaniasis or post kala-azar dermal leishmaniasis cases in India. Parasitol Res. 2012;111(4):1559-68.

7. Alvar J, Croft S, Olliaro P. Chemotherapy in the treatment and control of leishmaniasis. Adv Parasitol. 2006;61:223-74.

8. Banerjee A, De M, Ali N. Combination therapy with paromomycinassociated stearylamine-bearing liposomes cures experimental visceral leishmaniasis through Th1-biased immunomodulation. Antimicrob Agents Chemother. 2011;55(4):1661-70.

9. Jaafari MR, Bavarsad N, Bazzaz BSF, Samiei A, Soroush D, Ghorbani S, et al. Effect of topical liposomes containing paromomycin sulfate in the course of Leishmania major infection in susceptible BALB/c mice. Antimicrob Agents Chemother. 2009;53(6):2259-65.

10. Khan W, Sharma SS, Kumar N. Bioanalytical method development, pharmacokinetics, and toxicity studies of paromomycin and paromomycin loaded in albumin microspheres. Drug Test Anal. 2013;5(6):453-60.

11. Jhingran A, Chawla B, Saxena S, Barrett MP, Madhubala R. Paromomycin: uptake and resistance in Leishmania donovani. Mol Biochem Parasitol. 2009;164(2):111-7.

12. Carneiro G, Santos DC, Oliveira MC, Fernandes AP, Ferreira LS, Ramaldes GA, et al. Topical delivery and in vivo antileishmanial activity of paromomycin-loaded liposomes for treatment of cutaneous leishmaniasis. J Liposome Res. 2010;20(1):16-23.

13. Solomon M, Pavlotsky F, Leshem E, Ephros M, Trau H, Schwartz E. Liposomal amphotericin B treatment of cutaneous leishmaniasis due to Leishmania tropica. J Eur Acad Dermatol Venereol. 2011;25(8):973-7.

14. Ferreira LS, Ramaldes GA, Nunan EA, Ferreira LA. In vitro skin permeation and retention of paromomycin from liposomes for topical treatment of the cutaneous leishmaniasis. Drug Dev Ind Pharm. 2004;30(3):289-96.

15. Fusai $\mathrm{T}$ et al. Ultrastructural changes in parasites induced by nanoparticle-bound pentamidine in a Leishmania major/mouse model. Parasite. 1997;4(2):133-9.

16. Croft SL, Yardley V. Chemotherapy of leishmaniasis. Curr Pharm Des. 2002;8(4):319-42.

17. Shazad B, Abbaszadeh B, Khamesipour A. Comparison of topical paromomycin sulfate (twice/day) with intralesional meglumine antimoniate for the treatment of cutaneous leishmaniasis caused by L. major. Eur J Dermatol. 2005;15(2):85-7. 
18. Armijos RX, Weigel MM, Calvopiña M, Mancheno M, Rodriguez R. Comparison of the effectiveness of two topical paromomycin treatments versus meglumine antimoniate for New World cutaneous leishmaniasis. Acta Trop. 2004;91(2):153-60.

19. Schwarz C, Mehnert W, Lucks J, Müller R. Solid lipid nanoparticles (SLN) for controlled drug delivery. I. Production, characterization and sterilization. J Control Release. 1994;30(1):83-96.

20. MuÈller RH, MaÈder K, Gohla S. Solid lipid nanoparticles (SLN) for controlled drug delivery-a review of the state of the art. Eur J Pharm Biopharm. 2000;50(1):161-77.

21. Date AA, Joshi MD, Patravale VB. Parasitic diseases: liposomes and polymeric nanoparticles versus lipid nanoparticles. Adv Drug Deliv Rev. 2007;59(6):505-21.

22. Vivek K, Reddy H, Murthy RS. Investigations of the effect of the lipid matrix on drug entrapment, in vitro release, and physical stability of olanzapine-loaded solid lipid nanoparticles. AAPS PharmSciTech. 2007;8(4):16-24.

23. Manjunath K, Reddy J, Venkateswarlu V. Solid lipid nanoparticles as drug delivery systems. Methods Find Exp Clin Pharmacol. 2005;27(2):127-44.

24. Patel MN, Lakkadwala S, Majrad MS, Injeti ER, Gollmer SM, Shah ZA, et al. Characterization and evaluation of 5-fluorouracilloaded solid lipid nanoparticles prepared via a temperaturemodulated solidification technique. AAPS PharmSciTech. 2014;15(6):1498-508.

25. Ridolfi DM, Marcato PD, Justo GZ, Cordi L, Machado D, Durán N. Chitosan-solid lipid nanoparticles as carriers for topical delivery of tretinoin. Colloids Surf B: Biointerfaces. 2012;93:36-40.

26. Abdelbary G, Fahmy RH. Diazepam-loaded solid lipid nanoparticles: design and characterization. Aaps Pharmscitech. 2009;10(1):211-9.

27. Nair R, Kumar AC, Priya VK, Yadav CM, Raju PY. Formulation and evaluation of chitosan solid lipid nanoparticles of carbamazepine. Lipids Health Dis. 2012;11(1):1-8.

28. Montenegro L, Campisi A, Sarpietro MG, Carbone C, Acquaviva $\mathrm{R}$, Raciti $\mathrm{G}$, et al. In vitro evaluation of idebenone-loaded solid lipid nanoparticles for drug delivery to the brain. Drug Dev Ind Pharm. 2011;37(6):737-46.

29. Leng F, Wan J, Liu W, Tao B, Chen X. Prolongation of epidural analgesia using solid lipid nanoparticles as drug carrier for lidocaine. Reg Anesth Pain Med. 2012;37(2):159-65.

30. Ghadiri M, Fatemi S, Vatanara A, Doroud D, Najafabadi AR, Darabi M, et al. Loading hydrophilic drug in solid lipid media as nanoparticles: statistical modeling of entrapment efficiency and particle size. Int J Pharm. 2012;424(1):128-37.

31. Postigo JAR. Leishmaniasis in the World Health Organization Eastern Mediterranean Region. Int J Antimicrob Agents. 2010;36:S62-S5.

32. Ghadiri M, Vatanara A, Doroud D, Najafabadi AR. Paromomycin loaded solid lipid nanoparticles: characterization of production parameters. Biotechnol Bioprocess Eng. 2011;16(3):617-23.

33. Downey AS, Chong CR, Graczyk TK, Sullivan DJ. Efficacy of pyrvinium pamoate against Cryptosporidium parvum infection in vitro and in a neonatal mouse model. Antimicrob Agents Chemother. 2008;52(9):3106-12.

34. Schöler N, Hahn H, Müller R, Liesenfeld O. Effect of lipid matrix and size of solid lipid nanoparticles (SLN) on the viability and cytokine production of macrophages. Int J Pharm. 2002;231(2):167-76.

35. Dutta A, Bandyopadhyay S, Mandal C, Chatterjee M. Development of a modified MTT assay for screening antimonial resistant field isolates of Indian visceral leishmaniasis. Parasitol Int. 2005;54(2):119-22.

36. Khosravi A, Sharifi I, Barati M, Zarean M, Hakimi-Parizi M. Anti-leishmanial effect of nanosilver solutions on Leishmania tropica promastigotes by in-vitro assay. Zahedan J Res Med Sci. 2011;13(7):8-12.

37. Jain SK, Sahu R, Walker LA, Tekwani BL. A parasite rescue and transformation assay for antileishmanial screening against intracellular Leishmania donovani amastigotes in THP1 human acute monocytic leukemia cell line. J Vis Exp: JoVE. 2012(70).

38. Schwartz J, Moreno E, Fernández C, Navarro-Blasco I, Nguewa PA, Palop JA, et al. Topical treatment of L. major infected $\mathrm{BALB} / \mathrm{c}$ mice with a novel diselenide chitosan hydrogel formulation. Eur J Pharm Sci. 2014;62:309-16.
39. Croft SL, Coombs GH. Leishmaniasis-current chemotherapy and recent advances in the search for novel drugs. Trends Parasitol. 2003;19(11):502-8.

40. Croft SL, Olliaro P. Leishmaniasis chemotherapy-challenges and opportunities. Clin Microbiol Infect. 2011;17(10):1478-83.

41. Sundar S, Jha T, Thakur CP, Sinha PK, Bhattacharya SK. Injectable paromomycin for visceral leishmaniasis in India. N Engl J Med. 2007;356(25):2571-81.

42. Shah P, Bhalodia D, Shelat P. Nanoemulsion: a pharmaceutical review. Sys Rev Pharm. 2010;1(1):24.

43. Win KY, Feng S-S. Effects of particle size and surface coating on cellular uptake of polymeric nanoparticles for oral delivery of anticancer drugs. Biogeosciences. 2005;26(15):2713-22.

44. Ekambaram P, Sathali AAH, Priyanka K. Solid lipid nanoparticles: a review. Sci Rev Chem Commun. 2012;2(1):80-102.

45. El-On J, Jacobs G, Witztum E, Greenblatt C. Development of topical treatment for cutaneous leishmaniasis caused by Leishmania major in experimental animals. Antimicrob Agents Chemother. 1984;26(5):745-51.

46. Garnier T, Croft SL. Topical treatment for cutaneous leishmaniasis. Curr Opin Investig Drugs. 2002;3(4):538-44.

47. Müller RH, Rühl D, Runge S, Schulze-Forster K, Mehnert W. Cytotoxicity of solid lipid nanoparticles as a function of the lipid matrix and the surfactant. Pharm Res. 1997;14(4):458-62.

48. Müller SM RH, Weyhers H, Specht F, Lucks JS. Cytotoxicity of magnetite-loaded polylactide, polylactide/glycolide particles and solid lipid nanoparticles. Int J Pharm. 1996;138:85-94.

49. Weyenberg W, Filev P, Van den Plas D, Vandervoort J, De Smet $\mathrm{K}$, Sollie P, et al. Cytotoxicity of submicron emulsions and solid lipid nanoparticles for dermal application. Int J Pharm. 2007;337(1):291-8.

50. Karlsson HL, Gustafsson J, Cronholm P, Möller L. Sizedependent toxicity of metal oxide particles-a comparison between nano-and micrometer size. Toxicol Lett. 2009;188(2):1128.

51. Chithrani BD, Ghazani AA, Chan WC. Determining the size and shape dependence of gold nanoparticle uptake into mammalian cells. Nano Lett. 2006;6(4):662-8.

52. Lewinski N, Colvin V, Drezek R. Cytotoxicity of nanoparticles. Small. 2008;4(1):26-49.

53. Braydich-Stolle L, Hussain S, Schlager JJ, Hofmann M-C. In vitro cytotoxicity of nanoparticles in mammalian germline stem cells. Toxicol Sci. 2005;88(2):412-9.

54. Pan Y, Neuss S, Leifert A, Fischler M, Wen F, Simon U, et al. Size-dependent cytotoxicity of gold nanoparticles. Small. 2007;3(11):1941-9.

55. Lin W, Huang Y-w, Zhou X-D, Ma Y. In vitro toxicity of silica nanoparticles in human lung cancer cells. Toxicol Appl Pharmacol. 2006;217(3):252-9.

56. Carlson C, Hussain SM, Schrand AM, Braydich-Stolle KL, Hess $\mathrm{KL}$, Jones RL, et al. Unique cellular interaction of silver nanoparticles: size-dependent generation of reactive oxygen species. J Phys Chem B. 2008;112(43):13608-19.

57. Lee M-K, Lim S-J, Kim C-K. Preparation, characterization and in vitro cytotoxicity of paclitaxel-loaded sterically stabilized solid lipid nanoparticles. Biogeosciences. 2007;28(12):2137-46.

58. Jiang W, Kim BY, Rutka JT, Chan WC. Nanoparticle-mediated cellular response is size-dependent. Nature Nanotechnol. 2008;3(3):145-50.

59. Gebre-Hiwot A, Tadesse G, Croft S, Frommel D. An in vitro model for screening antileishmanial drugs: the human leukaemia monocyte cell line, THP-1. Acta Trop. 1992;51(3):237-45.

60. Berman JD, Wyler DJ. An in vitro model for investigation of chemotherapeutic agents in leishmaniasis. J Infect Dis. 1980;142(1):83-6.

61. Looker DL, Martinez S, Horton JM, Marr JJ. Growth of Leishmania donovani amastigotes in the continuous human macrophage cell line U937: studies of drug efficacy and metabolism. J Infect Dis. 1986;154(2):323-7.

62. Neal R, Croft S. An in-vitro system for determining the activity of compounds against the intracellular amastigote form of Leishmania donovani. J Antimicrob Chemother. 1984;14(5):463-75.

63. Berman JD. Leishmania tropica: quantitation of in vitro activity of antileishmanial agents by Giemsa staining, viability, and $3 \mathrm{H}-$ formycin B incorporation. J Parasitol. 1984;70:561-2. 